Check for updates

Cite this: RSC Adv., 2019, 9, 13263

\title{
Facile anion-exchange reaction in mixed-cation lead bromide perovskite nanocrystals
}

\author{
Ambra Pisanu, Paolo Quadrelli (D) and Lorenzo Malavasi (D) * \\ The present paper reports a facile and fast anion exchange reaction approach for perovskite nanocrystals \\ (NCs). The reaction has been applied to a mixed-cation sample, namely $\mathrm{FA}_{0.8} \mathrm{Cs}_{0.2} \mathrm{PbBr}_{3}$, and just \\ employs lead halide precursors to achieve a significant shift in the nanocrystals emission. Within 30 \\ minutes reaction time and a molar ratio between the NCs and the halide precursors of $1: 1$, it was \\ possible to cover more than $120 \mathrm{~nm}$ in the visible region. The exchanged NCs maintain their cubic- \\ shaped morphology and narrow emission peak width for the whole compositional range explored. The \\ present approach also allows a reduction in solvent use since it does not require any halide precursor \\ synthesis nor complex post-synthesis treatments.
}

Received 11th February 2019

Accepted 24th April 2019

DOI: $10.1039 / \mathrm{c} 9 \mathrm{ra01089k}$

rsc.li/rsc-advances

nanocrystals is their wide band gap tunability. Up to now the

\section{Introduction}

Lead halide semiconductors with a perovskite crystal structure have been thoroughly investigated during the last several years as a new class of optoelectronic materials. Starting with photovoltaic applications, with power conversion efficiencies beyond $22 \%$, they are now particularly attractive in applications such as light-emitting devices, lasers and photodetectors..$^{1-5}$ The majority of research has focused on bulk, single crystals and thin films perovskites, while colloidal synthesis to hybrid or to fully inorganic perovskite nanocrystals is a completely new method firstly reported in $2015 .{ }^{6}$ Controlled size reduction to the nanoscale dimension is a challenging issue because it gives rise to brand new and unique properties which pave the way for different research directions and applications.

Cesium and formamidinium lead halide nanocrystals have been shown to retain striking optical properties such as broadly tuneable photo-luminescence adjusting the nanocrystal size, small full-width at half-maxima and high photoluminescence (PL) quantum yields up to $90 \%$. In the future, the most viable application of these nanocrystals will be in television displays and related devices. ${ }^{6,7}$ Mixed cations perovskites show a significant enhancement of the power conversion efficiency and improved stability, in particular Zhang et al. proved that the optimized composition $\mathrm{FA}_{0.8} \mathrm{Cs}_{0.2} \mathrm{PbBr}_{3}$ exhibit a superior behaviour than others compositions in terms of high quantum efficiency, proper energy level and air stability, which together contribute to its outstanding luminance performance (55 005 $\mathrm{cd} \mathrm{m}^{-2}$ ) in the LEDs. ${ }^{8}$

Beyond the optical properties and the charming applications, one of the most appealing aspect of perovskites

Department of Chemistry, INSTM, Viale Taramelli 16, 27100, Pavia, Italy. E-mail: lorenzo.malavasi@unipv.it modulation of the band gap has been carried out above all at the synthesis step, by preparing different compositions or solid solutions of the cations or the anions. ${ }^{7-15}$ However, appealing post-synthetic strategies rely on the anion exchange of the prepared colloidal nano-dispersions, as it has been previously demonstrated on $\mathrm{CsPbBr}_{3} \cdot{ }^{16-22}$ One of the most common routes for anion exchange in lead halide nanocrystal was reported by Nedelcu et al. and makes use of Schlenk line where lead halogens and OAmX as anion sources were mixed with octadecene (ODE) in neck flask and kept under vacuum at $120^{\circ} \mathrm{C}$. The dried oleic acid (OA) and oleylamine (OLA) were injected at $120{ }^{\circ} \mathrm{C}$ under $\mathrm{N}_{2}$ flow. ${ }^{17}$ While this approach is highly suitable to provide a full anion exchange, it would be desirable to provide more easy and facile routes to perform such anion modification on lead halide nanocrystals and also provide evidence of such exchange on mixed cation compositions.

For these reasons, in this work we selected the $\mathrm{FA}_{0.8} \mathrm{Cs}_{0.2^{-}}$ $\mathrm{PbBr}_{3}$ optimized composition to perform a halide exchange reaction with $\mathrm{I}$ and $\mathrm{Cl}$ providing a facile and fast method to perform it.

\section{Experimental}

\section{Preparation of oleylammonium bromide (OAmBr)}

Ethanol (100 mL, Aldrich, absolute) and oleylamine (OLA, 12.5 $\mathrm{mL}$, Acros Organics) were combined in a 3-neck flask under vigorous stirring. The solution was cooled in an ice-water bath and $8.56 \mathrm{~mL} \mathrm{HBr}$ (48\% aqueous solution, Aldrich) were added very slowly and then the mixture was left to react overnight under $\mathrm{N}_{2}$ flow. The next day the reaction mixture was cooled again in an ice-water bath for 2 hours. The product (a white powder) was obtained after filtering, purifying by rinsing 
multiple times with diethylether and vacuum-drying at $60{ }^{\circ} \mathrm{C}$ in a Abderhalden's drying pistol overnight.

\section{Synthesis of $\mathrm{FA}_{0.8} \mathrm{Cs}_{0.2} \mathrm{PbBr}_{3}$}

It follows the typical hot-injection method described by Protesescu et al. in their work ${ }^{7}$ on formamidinium nanocrystals: a precursor solution was prepared using $\mathrm{Pb}(0.2 \mathrm{mmol})$, formamidinium (FA) $(0.6 \mathrm{mmol})$ and Cs $(0.15 \mathrm{mmol})$ acetates (Sigma Aldrich) with dried oleic acid ( $2 \mathrm{~mL}$, Acros Organics) and dried octadecene (8 mL, Acros Organics); at $130{ }^{\circ} \mathrm{C}$, under $\mathrm{N}_{2}$ flow, oleyl ammonium bromide $(0.6 \mathrm{mmol})$ dissolved in toluene $(2 \mathrm{~mL})$ was injected. After few seconds the nanocrystals were quenched in ice, to the crude solution were added $10 \mathrm{~mL}$ of toluene and $5 \mathrm{~mL}$ of acetonitrile and the mixture was centrifuged for $5 \mathrm{~min}$ at $12 \mathrm{k} \mathrm{rpm}$. The precipitate was dispersed in $5 \mathrm{~mL}$ of toluene.

\section{Exchange reactions}

The anion exchange reactions reported were conducted at room temperature in toluene by mixing a specific ratio of the desired lead halide salt. In particular, $0.113 \mathrm{mmol}$ of $\mathrm{PbX}_{2}$ were loaded in $4 \mathrm{~mL}$ of $\mathrm{FA}_{0.8} \mathrm{Cs}_{0.2} \mathrm{PbBr}_{3} \mathrm{NCs}$ toluene solution $28.3 \mathrm{mM}$, followed by 1, 5, 10, 15 and 30 minutes of vigorous stirring. The transparent dispersion was separated from the solid phase by centrifugation and analysed.

\section{X-ray diffraction}

The crystal structures of the samples were characterized by roomtemperature Cu-radiation Powder X-ray diffraction (XRD) on a Bruker D8 diffractometer. Scans were performed in the $10-40^{\circ}$ range, with a step size $0.04^{\circ}$ and a counting time of $3 \mathrm{~s}$ per step.

\section{Absorbance}

UV-Vis absorption spectra for colloidal solutions were run on Varian Cary 50 Scan spectrophotometer in absorbance mode with quartz cuvettes of $1 \mathrm{~cm}$ path length.

\section{Photoluminescence (PL)}

A PerkinElmer LS 50B spectrofluorimeter was used to acquire steady-state PL spectra from colloidal solutions.

\section{Transmission electron microscopy (TEM)}

TEM images were collected on a JEOL JEM-1200 EX II microscope operating at $100 \mathrm{kV}$ (tungsten filament gun) and equipped with the TEM CCD camera Olympus Mega View G2 with $1376 \times$ 1032 pixel format. Samples were prepared by drop-casting the solution on coated copper grids.

\section{Results and discussion}

The synthesis of the optimized $\mathrm{FA}_{0.8} \mathrm{Cs}_{0.2} \mathrm{PbBr}_{3}$ follows the typical hot-injection method described by Protesescu et al. in their work on formamidinium nanocrystals: a precursor solution was prepared using $\mathrm{Pb}, \mathrm{FA}$ and $\mathrm{Cs}$ acetates with dried oleic acid and dried octadecene; at $130{ }^{\circ} \mathrm{C}$ oleyl ammonium bromide dissolved in toluene was injected and after few seconds the nanocrystals were quenched in ice and purified. ${ }^{7}$ This simple synthesis allowed us to obtain luminescent cubic shaped nanocrystals (Fig. 1) with average size around $15 \mathrm{~nm}$. Both nanocrystal size and emission properties agree with the results reported previously for $\mathrm{FA}_{0.8} \mathrm{Cs}_{0.2} \mathrm{PbBr}_{3}{ }^{8}$

In Fig. $2 \mathrm{~A}$ are shown the XRD patterns of the $\mathrm{FA}_{0.8} \mathrm{Cs}_{0.2} \mathrm{PbBr}_{3}$ sample together with $\mathrm{FAPbBr}_{3}$ and $\mathrm{CsPbBr}_{3}$ prepared with the same method as well as the reference pattern of the orthorhombic cell found for these halides (space group, Pnma). Fig. 2B reports a selected region of the patterns in order to discuss better and highlight the effects of cation composition on lattice size. First of all, all the samples are single phase without detectable impurities. Moreover, from Fig. 2B, it can be appreciated that the (040) and (202) reflections of the reference pattern of $\mathrm{CsPbBr}_{3}$ (vertical red lines) are found in good agreement with the experimental data indicating the proper chemical composition of the sample. The same peaks are found at lower angle by replacing Cs with FA, indicating an increase of the cell size in agreement with the difference in the ionic radii between the two cations $\left(r_{\mathrm{Cs}}: 1.81 \AA, r_{\mathrm{FA}}: 2.79 \AA\right)$. Finally, the mixed sample, i.e. $\mathrm{FA}_{0.8} \mathrm{Cs}_{0.2} \mathrm{PbBr}_{3}$, is found at peak positions close to $\mathrm{FAPbBr}_{3}$ but at slightly higher angle, in agreement with the $20 \%$ Cs-content.

The optical properties of the $\mathrm{FA}_{0.8} \mathrm{Cs}_{0.2} \mathrm{PbBr}_{3}$ sample, together with the two end-members $\mathrm{CsPbBr}_{3}$ and $\mathrm{FAPbBr}_{3}$, have
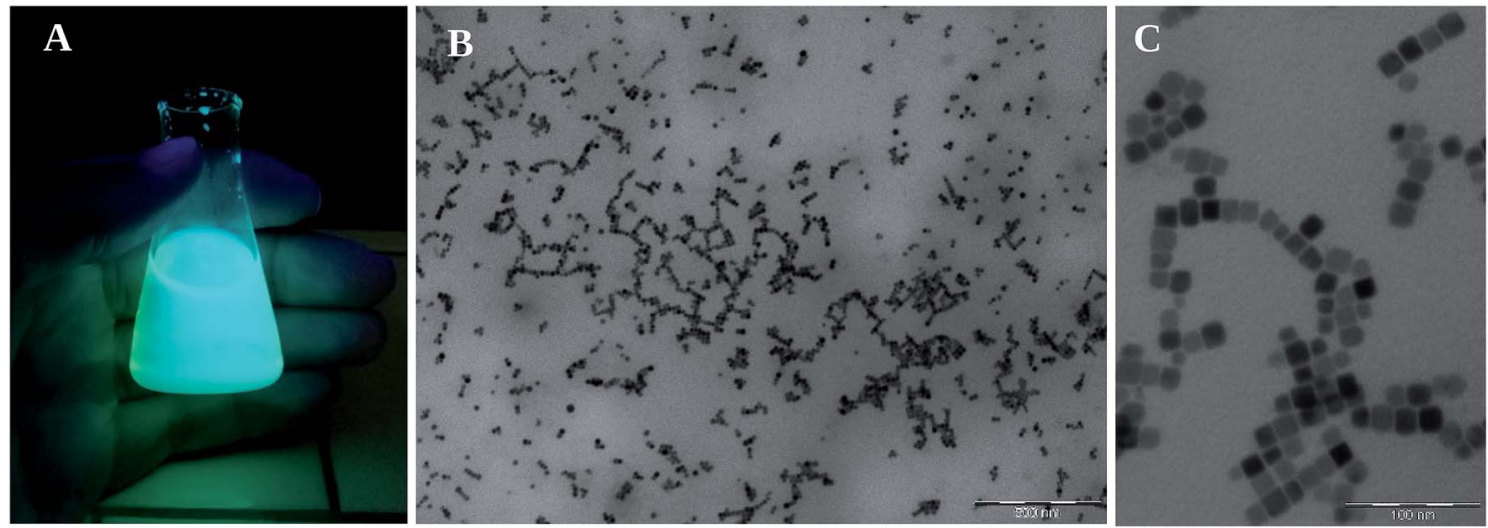

Fig. 1 (A) Dispersion of $\mathrm{FA}_{0.8} \mathrm{Cs}_{0.2} \mathrm{PbBr}_{3} \mathrm{NCs}$ in toluene under UV lamp; (B) and (C) TEM images of $\mathrm{FA}_{0.8} \mathrm{Cs}_{0.2} \mathrm{PbBr}_{3} \mathrm{NCs}$ 

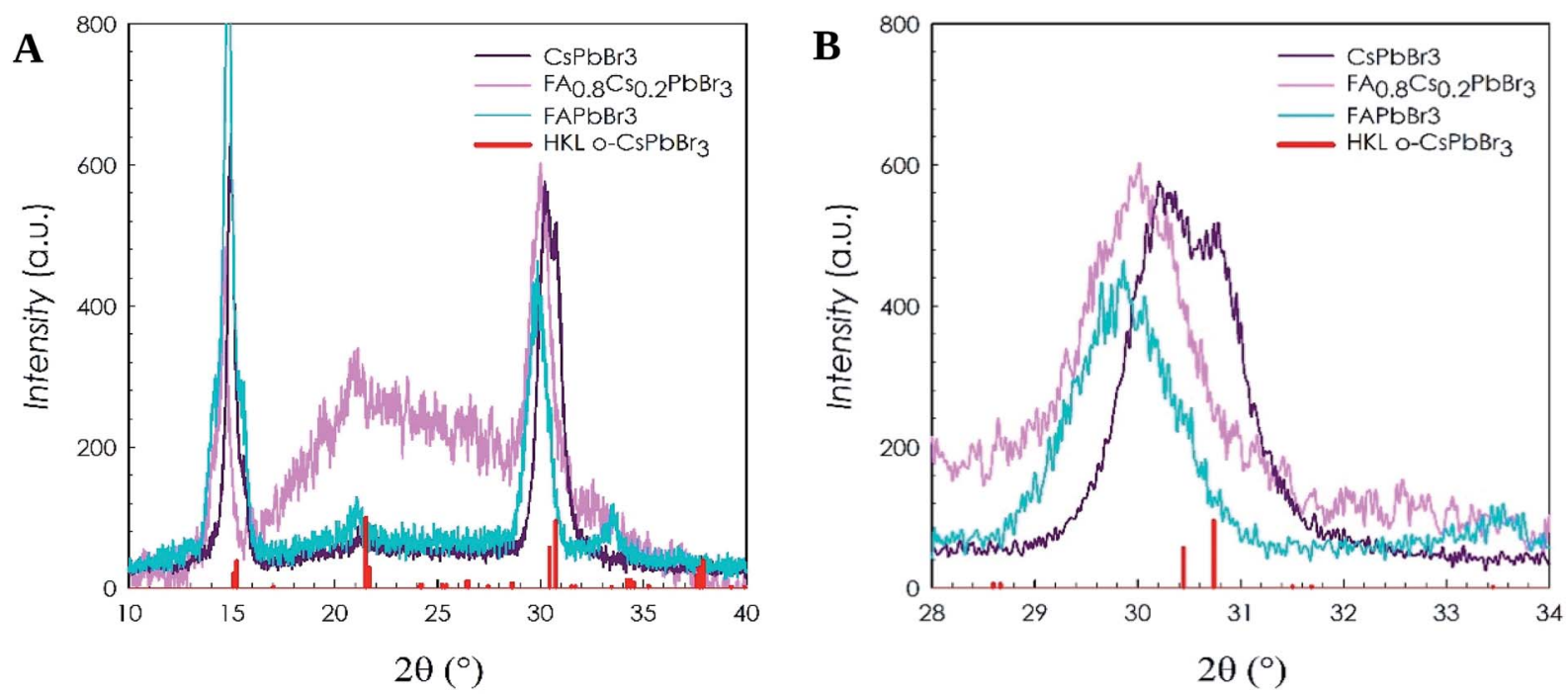

Fig. 2 (A) XRD patterns of $\mathrm{CsPbBr}_{3}, \mathrm{FAPbBr}_{3}$ and $\mathrm{FA}_{0.8} \mathrm{Cs}_{0.2} \mathrm{PbBr}_{3} \mathrm{NCs}$; (B) same XRD patterns zoomed around $30^{\circ}$.

been measured by means of PL spectroscopy. The results are reported in Fig. 3.

For all the three samples reported in Fig. 3, the PL shows a single narrow peak (FWHM $c a .10 \mathrm{~nm}$ ). The emission of pure $\mathrm{CsPbBr}_{3}$ is centred at about $513 \mathrm{~nm}$ in agreement with previous literature data for an analogous crystal size. ${ }^{6-8}$ On the other hand, the replacement of Cs with FA red-shift the emission peak initially to $2.38 \mathrm{eV}\left(\mathrm{FA}_{0.8} \mathrm{Cs}_{0.2} \mathrm{PbBr}_{3}\right)$ and then to $2.33 \mathrm{eV}\left(\mathrm{FAPbBr}_{3}\right.$ sample).

Now that the properties of the $\mathrm{FA}_{0.8} \mathrm{Cs}_{0.2} \mathrm{PbBr}_{3}$ starting sample have been properly characterized and compared to the data of the two end-members of the mixed compositions, we realized an anion-exchange reaction using lead halide precursors, with a simple dynamic solution process, a fast method to

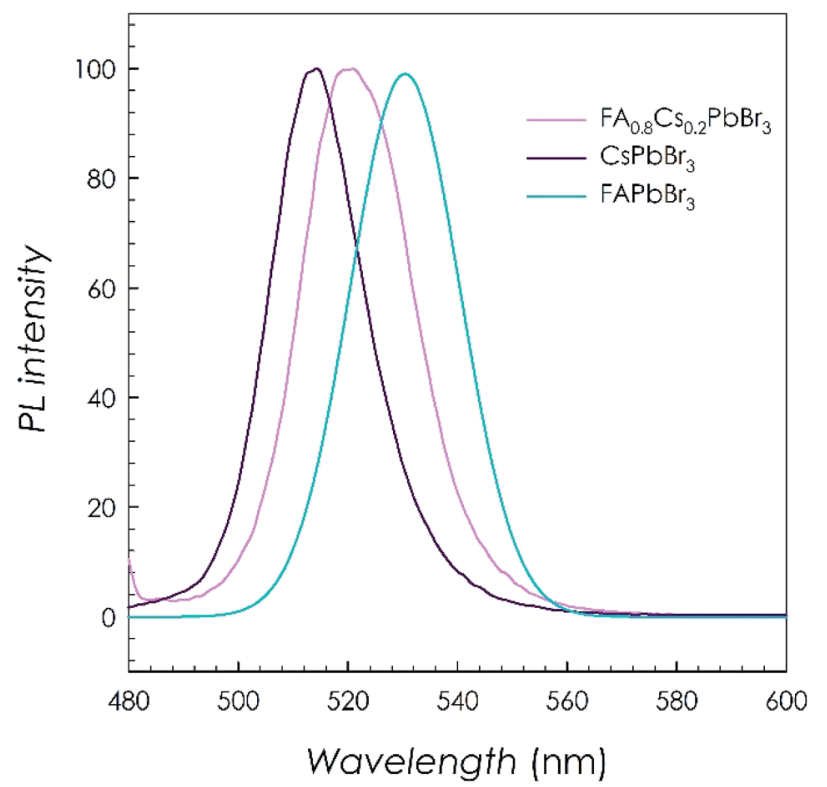

Fig. 3 Normalized $\mathrm{PL}$ spectra of $\mathrm{CsPbBr}_{3}, \mathrm{FAPbBr}_{3}$ and $\mathrm{FA}_{0.8} \mathrm{Cs}_{0.2} \mathrm{PbBr}_{3}$ tune the optical properties in a post-synthetic reaction with the preservation of the crystal structure and morphology.

The anion exchange reactions reported were conducted at room temperature in toluene by mixing a specific ratio of the desired lead halide salt. In particular, $0.113 \mathrm{mmol}$ of $\mathrm{PbX}_{2}$ were loaded in $4 \mathrm{~mL}$ of $\mathrm{FA}_{0.8} \mathrm{Cs}_{0.2} \mathrm{PbBr}_{3}$ NCs toluene solution $28.3 \mathrm{mM}$, followed by 10 seconds of vigorous stirring which were found to be enough to appreciate a first colour change suggesting the occurrence of anion exchange. After a minute the transparent solution was separated from the solid phase by centrifugation and analysed.

Compared to most of the reported methods, this one is facile, fast and environmentally friendly. ${ }^{16-24}$ The halide precursors do not need any solvent to be dissolved in, they can be separated by a simple filtration and, most relevant, the reaction can be carried out at room temperature and under ambient conditions. The products were characterized by means of X-ray diffraction, UV absorbance, photoluminescence and high resolution TEM.

Fig. 4 shows the appearance of mixed $\mathrm{Br} / \mathrm{Cl}$, pure $\mathrm{Br}$ and mixed $\mathrm{Br} / \mathrm{I}$ nanocrystals solutions under daylight and UV light illumination after 1 minute of exchange reaction. Already from

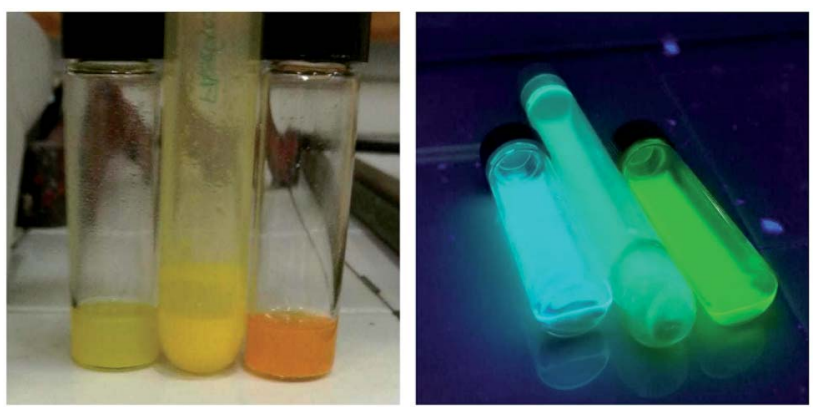

Fig. $4 \mathrm{FA}_{0.8} \mathrm{Cs}_{0.2} \mathrm{~Pb}(\mathrm{Br} / \mathrm{Cl})_{3}, \mathrm{FA}_{0.8} \mathrm{Cs}_{0.2} \mathrm{PbBr}_{3}$ and $\mathrm{FA}_{0.8} \mathrm{Cs}_{0.2} \mathrm{~Pb}(\mathrm{Br} / \mathrm{l})_{3}$ $\mathrm{NC}$ 's under daylight (left panel) and under UV light (right panel). 

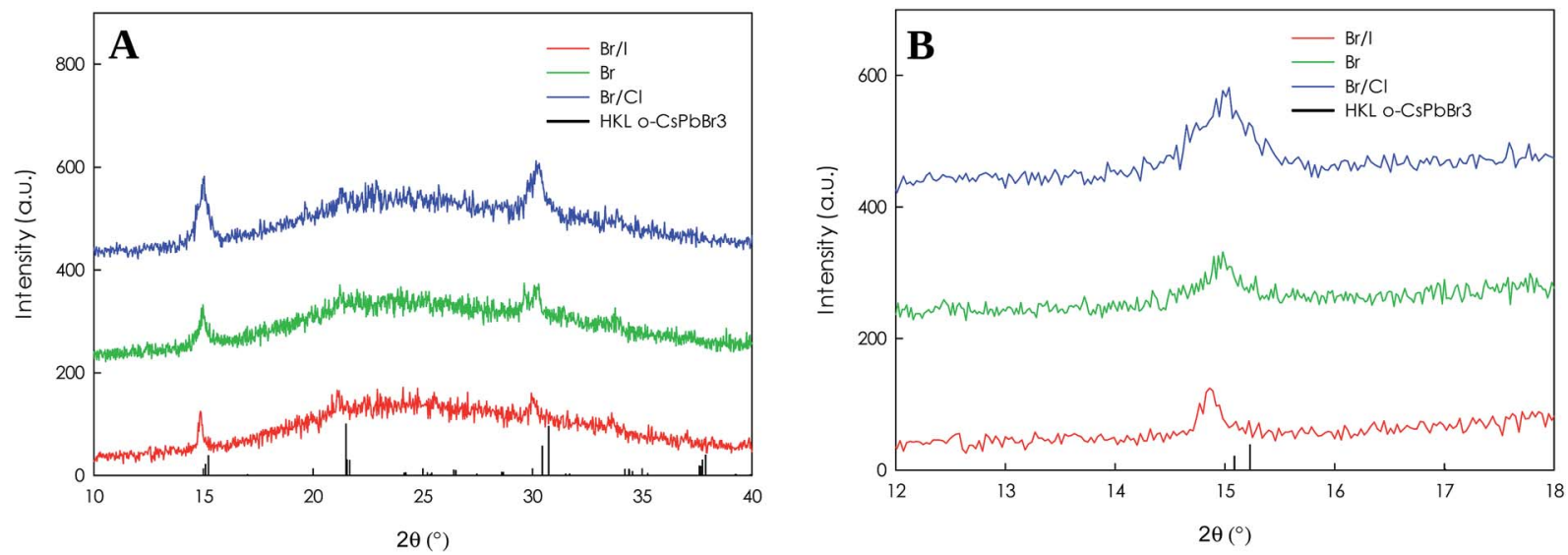

Fig. 5 (A) XRD patterns of $\mathrm{FA}_{0.8} \mathrm{Cs}_{0.2} \mathrm{PbBr}_{3}, \mathrm{FA}_{0.8} \mathrm{Cs}_{0.2} \mathrm{~Pb}(\mathrm{Br} / \mathrm{l})_{3}$ and $\mathrm{FA}_{0.8} \mathrm{Cs}_{0.2} \mathrm{~Pb}(\mathrm{Br} / \mathrm{Cl})_{3} \mathrm{NCs}$; (B) same XRD patterns zoomed around $15^{\circ}$.

this simple visual inspection, a blue-shift of $\mathrm{FA}_{0.8} \mathrm{Cs}_{0.2} \mathrm{PbBr}_{3}$ NCs is observed after the exchange with $\mathrm{Cl}$ ions while a red-shift of the emission is clear for the sample exchanged with I anions.

The XRD patterns reported in Fig. 5 for the $\mathrm{FA}_{0.8} \mathrm{Cs}_{0.2} \mathrm{PbBr}_{3}$, $\mathrm{FA}_{0.8} \mathrm{Cs}_{0.2} \mathrm{~Pb}(\mathrm{Br} / \mathrm{I})_{3}$ and $\mathrm{FA}_{0.8} \mathrm{Cs}_{0.2} \mathrm{~Pb}(\mathrm{Br} / \mathrm{Cl})_{3}$ NCs display the typical reflections of the orthorhombic perovskite structure of $\mathrm{CsPbBr}_{3}$. All the samples are single phase, anion exchange did not alter the crystal phase of the initial NCs. In Fig. 5B is reported a selected region to better analyse the effects of halide substitution: as expected the incorporation of $\mathrm{I}^{-}$cause an expansion of the cell and the peaks shift at lower angles, while upon the incorporation of $\mathrm{Cl}^{-}$, the cell shrunk, and the peaks shift to higher angles.

The optical properties of mixed $\mathrm{Br} / \mathrm{Cl}$, pure $\mathrm{Br}$ and mixed $\mathrm{Br} / \mathrm{I}$ nanocrystals have been measured by means of UV absorbance and PL spectroscopy. The results are reported in Fig. 6 . In the absorption spectra, with respect to Br-based NCs, the sample exchanged with Cl-ions shows a blue shift, while a red
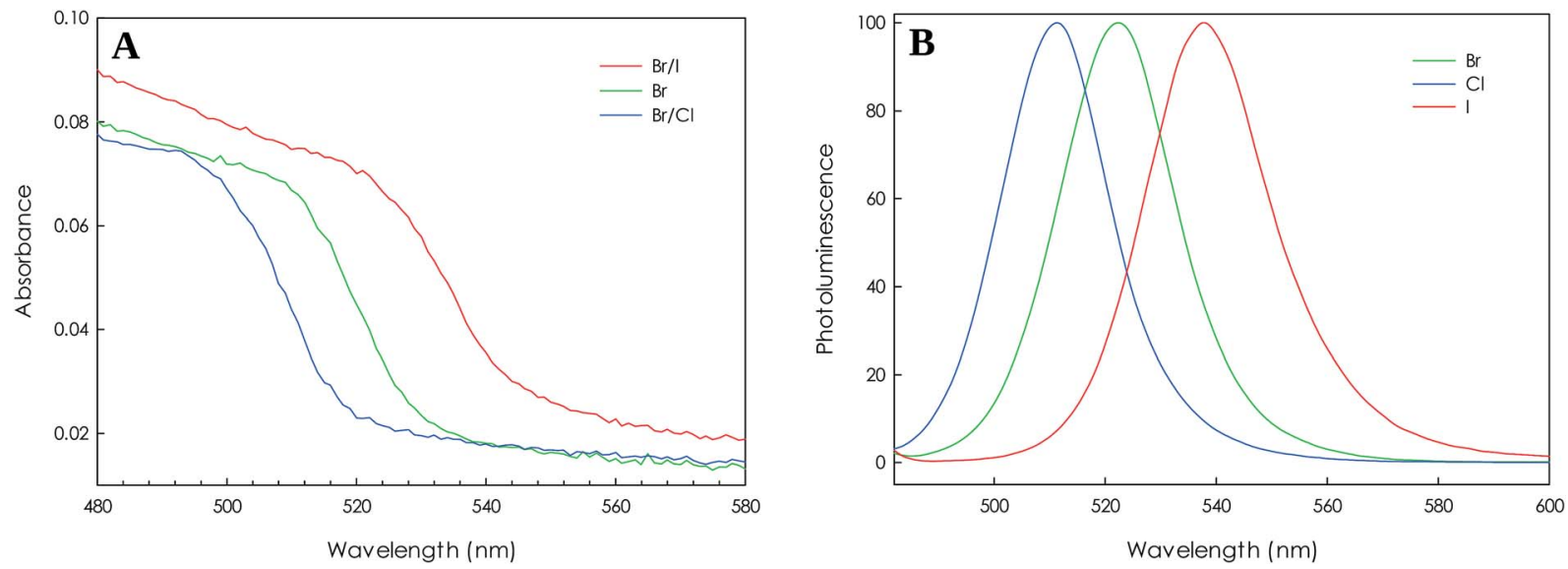

Fig. 6 (A) UV spectra and (B) normalized PL spectra of $\mathrm{FA}_{0.8} \mathrm{Cs}_{0.2} \mathrm{PbBr}_{3}, \mathrm{FA}_{0.8} \mathrm{Cs}_{0.2} \mathrm{~Pb}(\mathrm{Br} / \mathrm{I})_{3}$ and $\mathrm{FA}_{0.8} \mathrm{Cs}_{0.2} \mathrm{~Pb}(\mathrm{Br} / \mathrm{Cl})_{3} \mathrm{NCs}$.
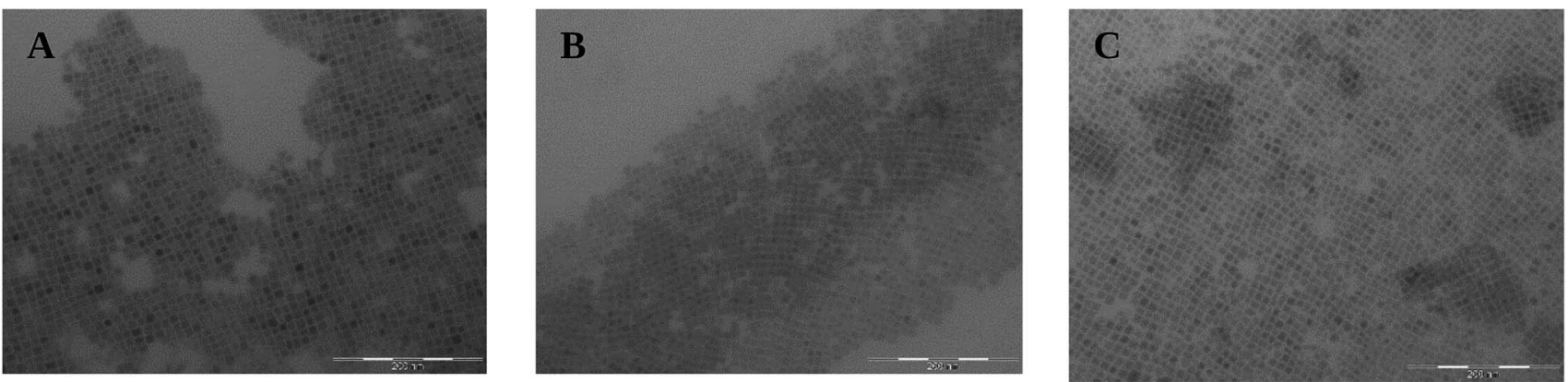

Fig. $7 \mathrm{TEM}$ images of (A); $\mathrm{FA}_{0.8} \mathrm{Cs}_{0.2} \mathrm{PbBr}_{3}$ (B) $\mathrm{FA}_{0.8} \mathrm{Cs}_{0.2} \mathrm{~Pb}(\mathrm{Br} / \mathrm{l})_{3}$ and $(\mathrm{C}) \mathrm{FA}_{0.8} \mathrm{Cs}_{0.2} \mathrm{~Pb}(\mathrm{Br} / \mathrm{Cl})_{3} \mathrm{NCs}$. 
shift is observed for the iodide one: the composition tuning of the samples enabled the band gap to display absorption over the range of $500-540 \mathrm{~nm}$ for a very short time of exchange reaction.

Along with the orthorhombic crystal structure, bright PL is retained, and the spectra are in good agreement with literature. For all the three samples reported the PL shows a single narrow peak (FWHM ca. $10 \mathrm{~nm}$ ). The emission of pure $\mathrm{Br}$ is centred at about $523 \mathrm{~nm}$; the replacement of Br with I red-shift the emission peak to $538 \mathrm{~nm}$ while the replacement with $\mathrm{Cl}$ blue-shift the peak to $511 \mathrm{~nm}$.

From the TEM images reported in Fig. 7, it is possible to observe that the morphology of the nanocrystals does not change, the cubic shape of the NC's whit bromide (Fig. 7A) is retained adding $\mathrm{PbI}_{2}$ and $\mathrm{PbCl}_{2}$ (Fig. 7B and C).

After assessing that this exchange methodology is effective in inducing an anion compositions modulation already for very short times (1 minute exchange), without changing the stoichiometry ratios between NCs and lead halide salts, the exchange was further investigated by increasing the reaction time to 5, 10, 15 and 30 minutes. The PL spectra of the samples for the corresponding reaction times and exchanged anions are reported in Fig. 8A, while Fig. 8B shows the appearance of the colloidal dispersions to which the PL spectra refer.

As can be appreciated, by simply increasing the stirring time the emission peaks significantly blue- and red-shift. Details about the PL peak maximum and FWHM are reported in Table 1. Overall, a $120 \mathrm{~nm}$ shift is achieved with this procedure and this mixing times. In addition, the peak widths remain quite narrow with a slight increase for the mixed $\mathrm{Br} / \mathrm{I}$ samples by increasing the exchange reaction time which however is around $13 \mathrm{~nm}$. An increase of the peak width for mixed $\mathrm{Br} / \mathrm{I}$ samples has been previously observed but with FWHM reaching values around $45 \mathrm{~nm}$ for mixed $\mathrm{Br} / \mathrm{I}$ samples. ${ }^{6}$ By comparing the actual PL emission values for the most exchanged samples with current literature for analogous crystal size, we may conclude that the maximum exchange level reached is around $1: 2 \mathrm{Br}: \mathrm{X}(\mathrm{X}=\mathrm{Cl}, \mathrm{I}) \cdot{ }^{16}$ This result is in agreement with the data reported by Akkerman and co-workers where, however, they employed for the exchange, octadecylammonium halides (ODA-X) precursors which requires a not trivial separate reaction step and a 20fold halide excess to achieve results analogous to those reported here. ${ }^{16}$ Still with reference to this last paper, the authors attempted as well the use of $\mathrm{PbX}_{2}$ salts for the exchange but concluded that the reaction was to slow and required more than 1 day to achieve a significant exchange and for this reason was not investigated. ${ }^{16}$ The reasons for this significant disagreement between the data reported here and previous literature is not clear and might be due to the different quality of the reagents employed.

It is clear that a lot of space if left to further investigate the simple and effective anion exchange reaction proposed here, such as, for example, by further increasing the reaction time or by changing the molar ratio between the precursor NCs and the lead halide source, which in the present case was fixed to $1: 1$.

Table 1 Emission properties and FWHM of the exchanged samples

\begin{tabular}{llll}
\hline Sample label & Emission $(\mathrm{nm})$ & Emission $(\mathrm{eV})$ & FWMH $(\mathrm{nm})$ \\
\hline Cl30 & 473.3 & 2.62 & 8.8 \\
Cl15 & 497.7 & 2.49 & 9.1 \\
Cl10 & 514.2 & 2.41 & 9.4 \\
Cl5 & 521.4 & 2.38 & 9.6 \\
Br & 522.3 & 2.37 & 11.0 \\
I5 & 541.5 & 2.29 & 10.9 \\
I10 & 565.8 & 2.19 & 12.3 \\
I15 & 571.3 & 2.17 & 12.7 \\
I30 & 605.7 & 2.04 & 13.9
\end{tabular}
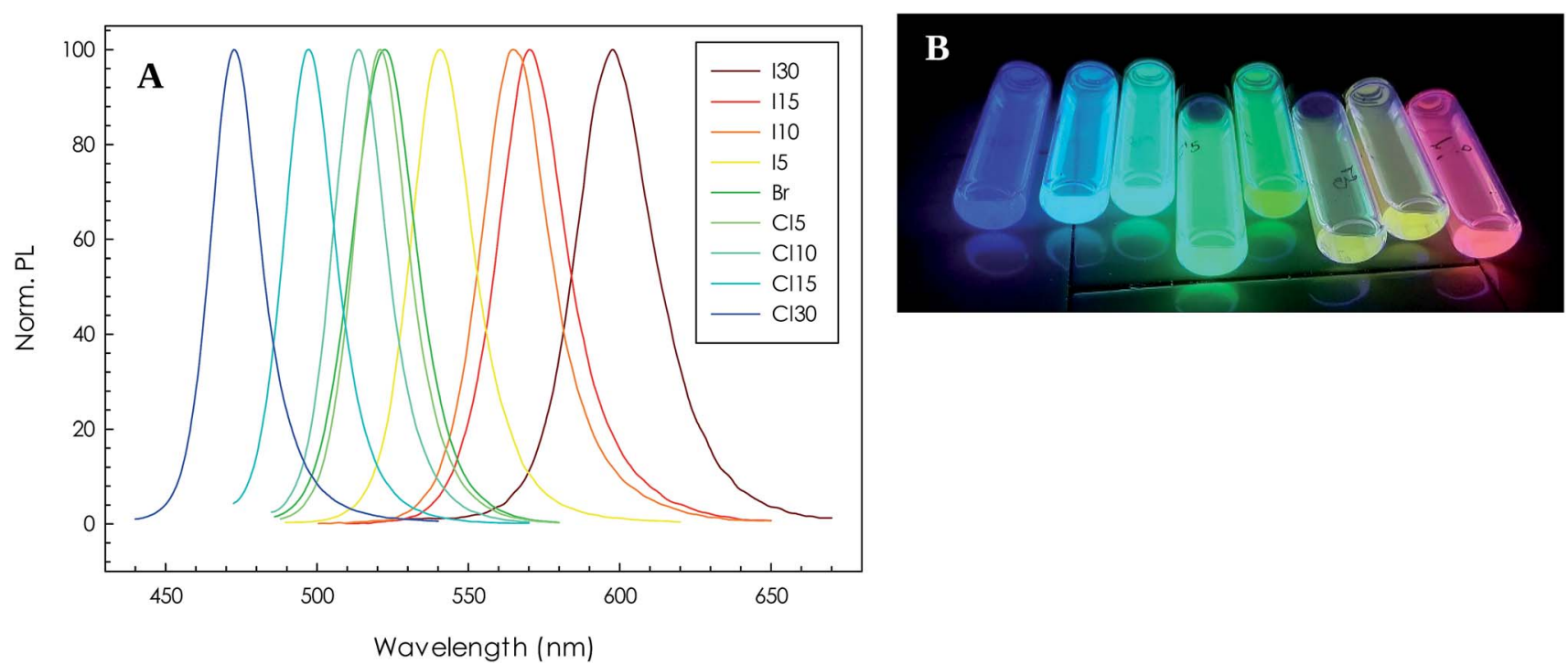

Fig. 8 (A) PL spectra of the $\mathrm{FA}_{0.8} \mathrm{Cs}_{0.2} \mathrm{~Pb}(\mathrm{Br}: \mathrm{X})_{3}\left(\mathrm{X}=\mathrm{Cl}\right.$, I) NCs prepared by anion exchange from $\mathrm{FA}_{0.8} \mathrm{Cs}_{0.2} \mathrm{PbBr}_{3} \mathrm{NCs}$ at different times (5, 10, 15 and 30 minutes); and (B) an image of the same samples under UV light. 


\section{Conclusions}

In summary, cubic shaped $\mathrm{FA}_{0.8} \mathrm{Cs}_{0.2} \mathrm{PbBr}_{3}$ NCs were synthesized by solution reaction with the hot-injection method. These NCs were transformed in $\mathrm{FA}_{0.8} \mathrm{Cs}_{0.2} \mathrm{~Pb}(\mathrm{Br} / \mathrm{I})_{3}$ and $\mathrm{FA}_{0.8} \mathrm{Cs}_{0.2^{-}}$ $\mathrm{Pb}(\mathrm{Br} / \mathrm{Cl})_{3}$ by a fast and simple post-synthetic halide exchange reaction using $\mathrm{PbI}_{2}$ and $\mathrm{PbCl}_{2}$ directly in the form of powders in a $1: 1$ molar ration with respect to the NCs with the preservation of shape and crystal structure of the starting sample.

The innovative aspects of this work are the conditions of the halide exchange reactions reported: they were conducted in toluene at room temperature, without the necessity of $\mathrm{N}_{2}$ atmosphere, with the simple use of lead halides thus not requiring the synthesis of complex halide precursors; in addition such precursors do not require the use of any solvent to be dissolved and the exchanged nanocrystals can be separated by a simple filtration or centrifugation.

By using the present NCs : halide precursors molar ratio and extending the reaction time to $30 \mathrm{~min}$ the exchanged nanocrystals covered a large part of the visible region of the spectrum, with a fine tuning of the emission with reaction time and by preserving a high quality of the final crystals with very narrow FWHM.

\section{Conflicts of interest}

There are no conflicts to declare.

\section{Acknowledgements}

We acknowledge the Centro Grandi Strumenti (CGS) of the University of Pavia for TEM measurements.

\section{References}

1 https:/www.nrel.gov/pv/assets/pdfs/pv-efficiencies-07-172018.pdf.

2 J. P. C. Baena, L. Steier, W. Tress, M. Saliba, S. Neutzner, T. Matsui, F. Giordano, T. J. Jacobsson, A. R. S. Kandada, S. M. Zakeeruddin, A. Petrozza, A. Abate, M. Khaja Nazeeruddin, M. Gratzel and A. Hagfeldt, Energy Environ. Sci., 2015, 8, 2928.

3 Z. K. Tan, R. S. Moghaddam, M. L. Lai, P. Docampo, R. Higler, F. Deschler, M. Price, A. Sadhanala, L. M. Pazos, D. Credgington, F. Hanusch, T. Bein, H. J. Snaith and R. H. Friend, Nat. Nanotechnol., 2014, 9, 687.

4 M. Saliba, S. M. Wood, J. B. Patel, P. K. Nayak, J. Huang, J. A. Alexander-Webber, B. Wenger, S. D. Stranks, M. T. Hörantner, J. Tse-Wei Wang, R. J. Nicholas, L. M. Herz, M. B. Johnston, S. M. Morris, H. J. Snaith and M. K. Riede, Adv. Mater., 2016, 28, 923.

5 R. Dong, Y. Fang, J. Chae, J. Dai, Z. Xiao, Q. Dong, Y. Yuan, A. Centrone, X. C. Zeng and J. Huang, Adv. Mater., 2015, 27, 1912.
6 L. Protesescu, S. Yakunin, M. I. Bodnarchuk, F. Krieg, R. Caputo, C. H. Hendon, R. X. Yang, A. Walsh and M. V. Kovalenko, Nano Lett., 2015, 15, 3692.

7 L. Protesescu, S. Yakunin, M. I. Bodnarchuk, F. Bertolotti, N. Masciocchi, A. Guagliardi and M. V. Kovalenko, J. Am. Chem. Soc., 2016, 138, 14202.

8 X. Zhang, H. Liu, W. Wang, J. Zhang, B. Xu, K. L. Karen, Y. Zheng, S. Liu, S. Chen, K. Wang and X. W. Sun, Adv. Mater., 2017, 29, 1606405.

9 A. Amat, E. Mosconi, E. Ronc, C. Quarti, P. Umari, M. K. Nazeeruddin, M. Grätzel and F. De Angelis, Nano Lett., 2014, 14, 3608.

10 M. Mittal, A. Jana, S. Sarkar, P. Mahadevan and S. Sapra, J. Phys. Chem. Lett., 2016, 7, 3270.

11 W. Van der Stam, J. J. Geuchies, T. Altantzis, K. H. W. van den Bos, J. D. Meeldijk, S. Van Aert, S. Bals, D. Vanmaekelbergh and C. de Mello Donega, J. Am. Chem. Soc., 2017, 139, 4087.

12 M. R. Linaburg, E. T. McClure, J. D. Majher and P. M. Woodward, Chem. Mater., 2017, 29(8), 3507.

13 T. C. Jellicoe, J. M. Richter, H. F. J. Glass, M. Tabachnyk, R. Brady, S. E. Dutton, A. Rao, R. H. Friend, D. Credgington, N. C. Greenham and M. L. Böhm, J. Am. Chem. Soc., 2016, 138, 2941.

14 Q. A. Akkerman, G. Rainò, M. V. Kovalenko and L. Manna, Nat. Mater., 2018, 17, 394.

15 L. Wang, N. E. Williams, E. W. Malachosky, J. P. Otto, D. Hayes, R. E. Wood, P. Guyot-Sionnest and G. S. Engel, ACS Nano, 2017, 11, 2689.

16 Q. A. Akkerman, V. D'Innocenzo, S. Accornero, A. Scarpellini, A. Petrozza, M. Prato and L. Manna, J. Am. Chem. Soc., 2015, 137(32), 10276.

17 G. Nedelcu, L. Protesescu, S. Yakunin, M. I. Bodnarchuk, M. J. Grotevent and M. V. Kovalenko, Nano Lett., 2015, 15(8), 5635.

18 Y. Bekenstein, B. A. Koscher, S. W. Eaton, P. Yang and A. P. Alivisatos, J. Am. Chem. Soc., 2015, 137(51), 16008.

19 S. E. Creutz, E. N. Crites, M. C. De Siena and D. R. Gamelin, Chem. Mater., 2018, 30, 4887.

20 D. Parobek, Y. Dong, T. Qiao, D. Rossi and D. H. Son, J. Am. Chem. Soc., 2017, 139(12), 4358.

21 M. Li, X. Zhang, K. Matras-Postolek, H.-S. Chen and P. Yang, J. Mater. Chem. C, 2018, 6, 5506-5513.

22 M. Li, X. Zhang, T. Dong, P. Wang, K. Matras-Postolek and P. Yang, J. Phys. Chem. C, 2018, 122, 28968-28976.

23 D. Zhang, Y. Yang, Y. Bekenstein, Y. Yu, N. A. Gibson, A. B. Wong, S. W. Eaton, N. Kornienko, Q. Kong, M. Lai, A. P. Alivisatos, S. R. Leone and P. Yang, J. Am. Chem. Soc., 2016, 138(23), 7236.

24 D. M. Jang, K. Park, D. H. Kim, J. Park, F. Shojaei, H. S. Kang, J. P. Ahn, J. W. Lee and J. K. Song, Nano Lett., 2015, 15, 51915199. 